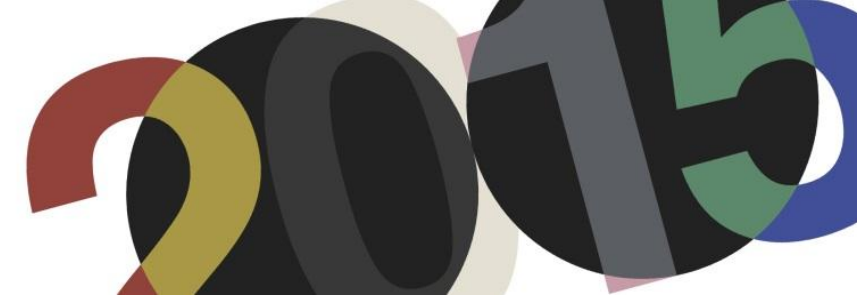

DOI: http://dx.doi.org/10.4995/LC2015.2015.668

\title{
HABITAR EL AIRE
}

\author{
M. Pérez Rodríguez
}

Escuela Superior de Arquitectura de Valencia

\begin{abstract}
Resumen: Existen en las ideas enunciadas por Le Corbusier dos caminos que partiendo aparentemente de mundos paralelos y opuestos, terminarán convergiéndo en un mismo lugar.

Con la construcción del Pavillon de l'Esprit Nouveau, en 1925, se define el nuevo espacio exterior vinculado a la vida moderna. Éste, se dará simultáneamente desde lo colectivo, el immeuble-villa, y desde lo individual, la villa, aunque ambos, se suceden como procesos coexistentes. A este vacío, Le Corbusier lo denominará jardin suspendu, y el orden con el cuál se definirá, será el mismo con el que se constituirá todo el sistema. Desde dentro, este jardin, dejará de ser un exterior para concebirse desde las mismos mecánismos que operan dentro de la casa. Entonces ¿Qué es este espacio?. Simplemente, lo que Le Corbusier trazó, una rica dualidad espacial.

Al otro lado, y opuesto a la casa, surge siempre un exterior, como extensión infinita de lo natural. ¿De qué forma ordenarlo? ¿cómo vincularlo de nuevo al hombre?. Sólo existe una respuesta posible, un único gesto, el arquitectónico, surgido con la construcción de un plano. Con él, asoma la vertical y la horizontal: Aquellas líneas que vinculan de nuevo al hombre con sus leyes. Con ello, el vacío ya no existe, se ha transformado, constituyendo un nuevo espacio. ¿Qué es este espacio?. De nuevo, una rica ambigüedad.
\end{abstract}

Abstract: Into the ideas enunciated by Le Corbusier there are two paths starting apparently from parallel and opposite worlds, but finally coming to converge in a same place.

With the construction of the "Pavillon de l'Esprit Nouveau", in 1925, it is defined the new outside space linked to modern life. This is given simultaneously from the collective with the "immeuble-villa", and from the individual, la villa, although both succeed as coexistent processes. This emptiness was called by Le Corbusier "jardin suspendu", and the order to define it, will be the same used to build the whole system.

From inside, this garden will fail to be an outside to be conceived from the same mechanisms that work into the house. So, what is this space? It is simply what Le Corbusier designed, a rich space duality. In the other side, and opposite the house, an outside emerges always, like a boundless extent of the natural. Which way can it be arranged? How can it be linked again to the human? It exists only one possible answer, one unique gesture, the architectonic one, which emerges with the construction of a plan. With it, vertical and horizontal positions arise: those lines that link again the man with his laws. With it, this emptiness doesn't exists anymore, it has changed becoming in a new space. What is this space? Again, a rich ambiguity.

Palabras clave: immeuble-villa, jardin suspendu, interior, exterior, dualidad especial.

Keywords: immueble-villa, jardin suspendu, inside, outside, space duality.

\section{Introducción}

Con motivo de la l'Exposition des Arts Décoratifs de París de 1925 Le Corbusier construye el Pavillon de L'Esprit Nouveau. Esto supone para él la cristalización de la idea de la cellule d'habitation enunciada en 1922 junto a su prototipo de immueble-villa y, el modelo de Ville Contemporaine de 3 Millions d'Habitants. Con ello, su primer objetivo, integrar urbanismo y arquitectura dentro de una misma disciplina, se cumple, asumiendo así que la concepción del nuevo microcosmos, la cellule, será la base indispensable para lograr tal fin: "[ [...] expresar el diseño de un edificio de viviendas mediante la construcción de un solo elemento y, utilizarlo para 
demostrar la tesis de la casa moderna",

La nueva idea, una casa llena de aire, constituye la esencia de muchos de sus futuros trabajos, tanto en lo referente a la vivienda colectiva o el immeuble, como a la villa individual. Basta con recordar las palabras que expresará Gideon tras visitar el Quartier Pessac, donde observará que en las casas de Le Corbusier " el aire circula a través de ellas. El aire se convierte en un factor esencial. Lo que cuenta no es ni el espacio ni la materia, sino las relaciones y las penetraciones [...] No existe ninguna diferencia entre el interior y el exterior" ${ }^{2}$. Es con relación a este proceso de doble inclusión entre el mundo exterior y el interior, cristalizado en el espacio que él denominará jardin suspend $u^{3}$, desde donde se aborda el análisis de su obra. Para él, la imagen ya ha quedado grabada en su retina y en su memoria, cuando habla de la Cartuja de Ema: "Cada casa posee de esta manera su propio jardín, en el que la intimidad es perfecta, como en el de los hermanos de la Cartuja de Emaen Galuzzo, cerca de Florencia, visitada por primera vez en 1907, en donde nos sentiamos invadidos por la melancolía. La belleza, la alegría, la serenidad se concentran aqui" "4.

Para el Le Corbusier de los años 20, el jardin suspendu será un proceso de racionalización de la naturaleza, un continuo desarrollo que irá en primer lugar a reconocer una visión de la naturaleza opuesta a la casa ${ }^{5}$, y en segundo término -con la búsqueda de un orden ${ }^{6}$ - la definición de un sistema que lo posibilite. Ese será el recorrido para llegar al nuevo espacio exterior de la casa moderna ${ }^{7}$,pero que como en cualquier proceso cíclico, éste germina desde sus primeras obras.

Si atendemos a las palabras utilizadas por Le Corbusier para describir el jardín de la villa Jeanneret-Perret - la Maison Blanche-, construída para sus padres en 1912 en La-Chaux-de-Fonds, fija las ideas que definirán este espacio:"completamente a salvo de miradas indiscretas, con vistas panorámicas de montañas y orientado para permitir una vida constante de la mañana a la noche al abrigo del viento, en un piso de baldosas siempre seco en medio de lechos de flores y praderas de pastos ${ }^{\prime \prime}$. La descripción, como primera aproximación genérica, valdría para cualquiera de sus posteriores jardin suspendu. Para lograr este propósito, se han de cumplir los tres requisitos básicos: se elevarán siempre por encima de la cota cero; se concebirán desde el orden geométrico y

\footnotetext{
1 “[...] d'exprimer la conception d' un bloc d'habitation en construisant un élément isolé et en s'en servant pour faire la démonstration des thèse du logis moderne”. Boesiger, Willy; Stonorov, O: Le Corbusier et Pierre Jeanneret.Oeuvre Complète. 1910-1929, $11^{\circ} \mathrm{Ed}$, Zurich: Les Éditions d'Architecture, 1973. p.92.

${ }^{2}$ Moss, Stanislau Von: Le Corbusier, $1^{\circ}$ Ed, Barcelona: Lumen, 1977, p.103. extraído de la cita 59, Bauen in Frankreich, p.8586. Fuentes de Pessac.

${ }^{3}$ Conviene adelantar que la denominación de jardin suspendu, tendrá múltiples acepciones a lo largo de todos los proyectos: jardin suspendu, jardin suspendu et couvert, jardin couvert, terrasse-jardin couverte, terrasse couverte, jardin-terrasse, o jardin supérieur ..etc.

${ }^{4}$ Giuliano Gresleri: Le Corbusier. Viaggio in Oriente, Paris:Foundation Le Corbusier, 1984.p.85

5 "une maison qui soit cette limite humaine, nous entourant, nous séparant du phénomène naturel antagoniste, nous donnant notre milieu humain, à nous hommes”. Le Corbusier: Hacía una Arquitectura,2ed, Barcelona: Apóstrofe, 1998, p.45.

6 "Que voyez-vous se dérouler sous vos yeux, sinon une immense mise en ordre? Lutte contre la nature pour la dominer, pour classer, pour se donner ses aises, en un mot, pour s'installer dans un monde humain qui ne soit le milieu de la nature antagoniste? Un monde à nous, d'ordre géométrique?'. Le Corbusier: Almanach d'Architecture Moderne,Paris:Les éditions G. Cres et Cia.1925 p.26.

7 "Con la terraza-jardin, el visitante aborda el espacio más prestigioso de la villa, el que otorga todo su sentido al proyecto. Lugar de calma y reposo, verdadero "salón a cielo abierto" para las recepciones de verano, este espacio resguardado de las miradas desde el parque, responde a toda una serie de exigencias de proyecto". Sbriglio, Jacques: Le Corbusier. La villa Savoye. Madrid: ABADA editores.2005.p.89

8 "totalement à l'abri des regards extérieurs, avec vue panoramique sur les chaînes de montagnes et orienté de façon à permettre un séjour constant du matin au soir à l'abri du vent, sur un sol dallé toujours sec au milieu de plates-bandes de fleurs et de parterres de gazon " Charles-Edouard Jeanneret, aviso de venta, el 21 de Enero de 1919. http:// www. maisonblanche.ch
} 
espacial del proyecto y; serán siempre un espacio delimitado. Pero aún con estas tres invariantes, este breve estudio analiza, además de los cambios del espacio en sí mismo, su interrelación con la vivienda. Los pequeños cambios no se darán sólo dentro de una misma obra, sino que la investigación en unos implicará la futura materialización de otros, reconociendo con ello, que el proyecto en Le Corbusier es siempre fruto de un un proceso abierto.

\section{Del lleno al vacío: El “Jardin suspendu”.}

\subsection{En el immeuble-villa.}

Cuando Le Corbusier concibe su immeuble-villa, apenas había construído un limitado número de viviendas en su Suiza natal. Pero sin embargo ya había enunciado, lo que sería sin duda la idea más relevante dentro de su obra: la Maison Dom-Ino. Lo más importante de la propuesta no estaba sólo en ofrecer un modelo estructural junto a su amigo Marc Dubois, sino la concepción de un sistema capaz de definir las claves de la vivienda moderna. Éstas se encontraban condensadas en la búsqueda de una heterogenidad y variación interior, en una libertad de su adaptación urbana y, por último, en una nueva forma de relación entre el interior y el exterior. Esta última es la que provocaría la nueva dualidad espacial, una dualidad generada por la utilización de divisiones transparentes y vidriadas, que como bien expresa G.Kepes, lograron "amplificar ópticamente esta integración y crear un espacio vivo y fluido, articulado por dentro y por fuera [...] crear una única unidad viviente","

Este proceso de inclusión espacial, y de simultaneidad perceptiva, ya estaba presente en otras realizaciones. En el ámbito de lo pictórico, por ejemplificarlo brevemente, esta sincronía ya se manifestaba gracias al uso del entrelazamiento de lineas y planos, o de la combinación entre oscuro y claro. Por ello, tanto Ozenfant como Le Corbusier al final de su primera etapa Purista (1918-28), se valdrán del uso de una línea de contorno común que entrelazará los distintos objetos formales dispuestos en el espacio de la tela. Este nuevo contorno presentaba un significado claro: crear una nueva unidad espacial.

Así será como la cualificación del espacio moderno será aprehendida por el habitante gracias al uso de esta mútua interrelación que, de otro lado, incorporará el espacio exterior como una nueva necesidad vital.

¿Por qué esta inclusión del jardin dentro de la vida urbana?. Una primera intención, sería rememorar "racionalmente" la relación del hombre con la naturaleza, una naturaleza controlada, aunque, conviene matizar, que esta idea de jardin ordenado se nutre también con lo no planificado. Las jardineras geométricas utilizadas por Le Corbusier serán las encargadas de ordenar el espacio del jardin y matizar las relaciones. Junto a esa búsqueda ordenada, la vegetación crecerá libremente en su interior y así lo expresará en su artículo Toitsjardins?:"El viento, los pájaros y los insectos traen semillas. Algunas de ellas encuentran un ambiente favorable. Los rosales se han sublevado y se han convertido en enormes escaramujos. El césped se ha convertido en hierba, en dientes de león. Un cítiso ha nacido, un falso sicomoro. Dos briznas de lavanda se han convertido en matorrales. El sol domina, el viento (allá arriba) domina. Las plantas y los arbustos se orientan y se instalan a su gusto, según sus necesidades. La naturaleza ha recobrado sus derechos. Desde este momento, el jardin está abandonado a su destino." $" 10$

\footnotetext{
${ }^{9}$ Kepes, G: El lenguaje de la visión, $1^{\circ}$ ed, Buenos Aires: Infinito, 1969. p.54.

${ }^{10}$ Boesiger, Willy; Stonorov, O: Le Corbusier et Pierre Jeanneret.Oeuvre Complète. 1910-1929, $11^{\circ}$ Ed, Zurich: Les Éditions d'Architecture, 1973.p.140
} 
Volviendo a la concepción del jardin, además de esta sutil domesticación de lo natural, también cualificará la vida del hombre moderno, individualizándolo de lo colectivo, y permitiendo que la máquina moderna tome aire - le machine à souffler-. Es decir, recuperará el aliento, construyendo el lugar para el ocio y el reposo, al igual que la ciudad moderna, una cavidad, llena de aire y de sol, que horadará sistemáticamente el bloque, como parte fundamental del problema de la vivienda ${ }^{11}$.
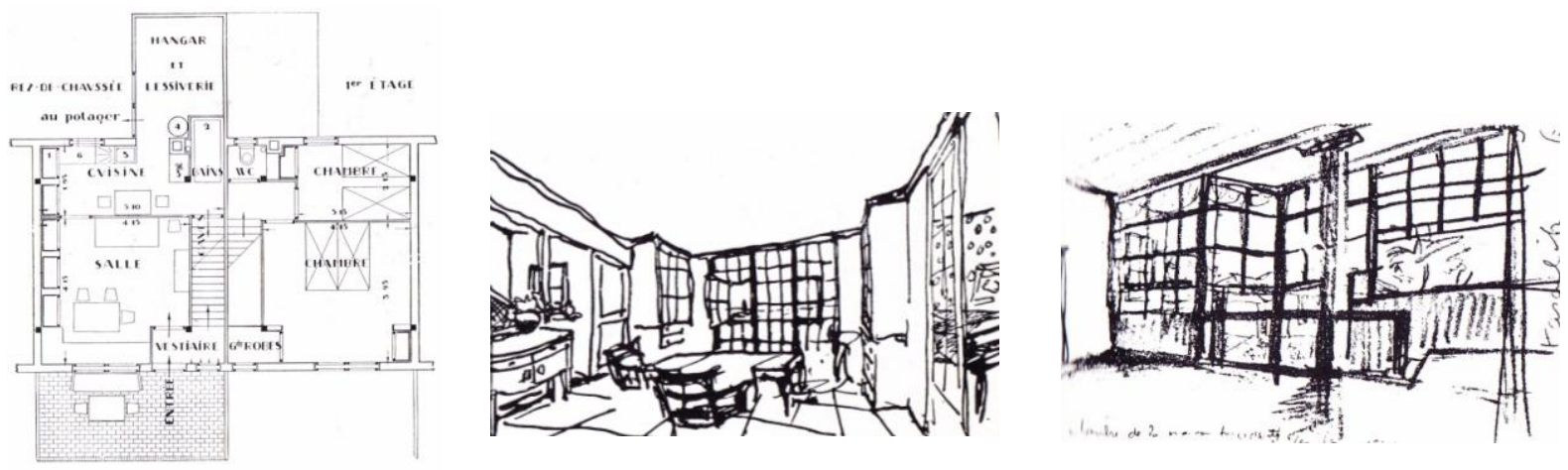

1. Type A (CFLC/ADAGP19176a), Rez-de-Chaussé et $1^{\circ}$ étage, Oeuvre Complète,vol.1, p.25.

2. Croquis $\odot$ FLC/ADAGP intérieur d'une maison dom-Ino, Oeuvre Complète,vol.1, p.25

3. Croquis OFLC/ADAGP5890, intérieur de la maison à Kasanlak, Oeuvre Complète,vol.1, p.17.

¿Cómo se producirá la nueva relación entre el interior y el exterior?. Si analizamos detenidamente los textos y diseños recogidos en su carnet A2, de entre los modelos de viviendas concebidos dentro del sistema dom-Ino, surge el type A (@FLC/ADAGP19176A)(1) como un único espacio construido con una mínima estructura de 4 pilares -una cella moderna del megaron clásico-. Un"Péristyle y hangar”, que tal y como indica J. Quetglas, se convierte en ese "maravilloso anacronismo, que relaciona la casa griega y romana con la arquitectura industrial " ${ }^{\prime 2}$. Gracias a este peristilo moderno se produce el acceso al type, disponiendo como extensión a él, la terrasse o el espacio exterior. Éste, a su vez, mantendrá una estrecha vinculación con el mundo interior gracias al estudio modular de la fenêtre (2). La propuesta dibujada recuerda bastante al boceto realizado por un joven $C h-\hat{E}$. Jeanneret, en el interior de la maison à Kasanlak (CFLC /ADAGP5890)(3) durante su viaje de 1911 por los Balcanes. Allí expresa y anuncia su interés por “une fenêtre plus longue que haute..." ${ }^{\prime 3}$, es decir, su futura fenêtre en longueur. Incluso, el mismo boceto, es recogido años más tarde en el primer volumen de la Oeuvre Complète $^{14}$. Así será como la superficie límite entre ambas realidades, se convierte en el principal problema a resolver dentro de la arquitectura.

\footnotetext{
11 "un espacio útil al aire libre [...] como uno de los elementos fundamentales en el problema de la vivienda míníma " Aymonino, Carlo: La vivienda racional. Ponencias de los Congresos CIAM 1929-1930. Análisis de los elementos fundamentales en el problema de la "vivienda minima". Le Corbusier y Pierre Jeanneret,Barcelona:Gustavo Gili, S.A.p.138. 12 "un merveilleux anachronisme qui relie la maison grecque et romaine à l'architecture industrielle”, Quetglas,Josep: Le Corbusier Plans, volumen 1,1905-1926.DVD, Paris:Fundation Le Corbusier, Echelle-1, 2005.

${ }^{13}$ Udovicki-Selb, Danilo François. Les Balkans, génese des cinc points de l'architecture. l'invention d'une architecte. Le voyage en Orient de Le Cobusier, Paris:Editions de la Vilette, cop.2013.p.212

${ }^{14}$ Boesiger, Willy; Stonorov,O: Le Corbusier et Pierre Jeanneret.Oeuvre Complète. 1910-1929, $11^{\circ}$ Ed, Zurich: Les Éditions d'Architecture, 1973,p.17
} 

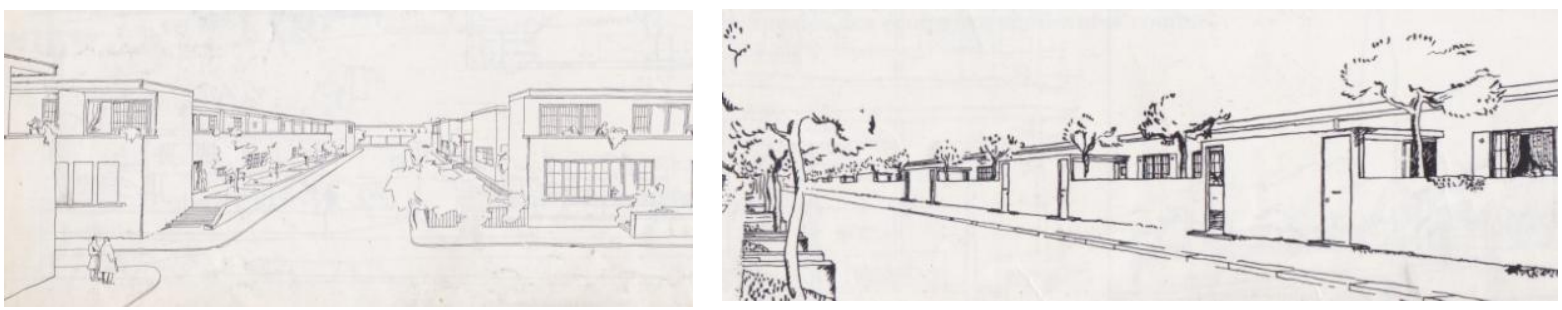

4. CFLC/ADAGP19221 Maison Dom-Ino. Propuesta de ordenación y volumetrías, Oeuvre Complète, p. 26 5.C FLC/ADAGP07856, Alz. propuesta Cité ouvrière, 1920, Oeuvre Complète,p.29

Dentro del grupo de propuestas maison ouvrière que proyectará en los años anteriores a 1922, ya se comprueba el valor que adquieren las decisiones sobre la disposición del espacio exterior, o el tipo de fenestración utilizado. En algunos casos, la solución remite a una composición clásica (@FLC/ADAGP 19221) (4). En otras, como en la Cité Ouvrière en Grand Couronne ${ }^{15}$ de 1920 (CFLC/ADAGP 07856)(5), la colocación de un espacio exterior previo, delimitado y métricamente modulado al resto del proyecto, habla más de la ley de la repetición. Estas indagaciones son, si cabe, un adelanto a los futuros equilibrios plásticos, entre el vacío y el lleno, de las posteriores fachadas del immeuble-villa.

Adentrándonos de nuevo en la cellule del immeuble-villa, y en cómo ese espacio exterior irá transformando su relación con el mundo interior de la casa, el camino arranca con la construcción del Pavillon de L'Esprit Nouveau. Éste se concibe como una villa individual, capaz de ser superpuesta, donde el jardin suspendu se convertirá en la foyer exterior adyacente a la casa.

El espacio medido matemáticamente forma parte de la métrica general del sistema, donde el jardin ocupará la serie BA -en sentido longitudinal- y BBB -en transversal-; constituyéndose la caja de 71/2 $\times 7 \frac{1}{2}$. En definitiva, un espacio de geometría cúbica, que propicia que el aire penetre hasta el corazón mismo del bloque. Pero además, ese espacio matemático, también será medido "emocionalmente" y de ahí que Le Corbusier, trabaje sobre los límites laterales de esta caja, unos límites que apenas se perforarán.

Esta idea mantiene una de las lecciones aprehendidas por Le Corbusier en su viaje a Pompeia, ya que en su visita a la maison des Dioscures, el arquitecto boceta y describe el salón de la villa como "un único y bello espacio surgido de sus precisas proporciones, y de la masa que lo envuelve” (6).
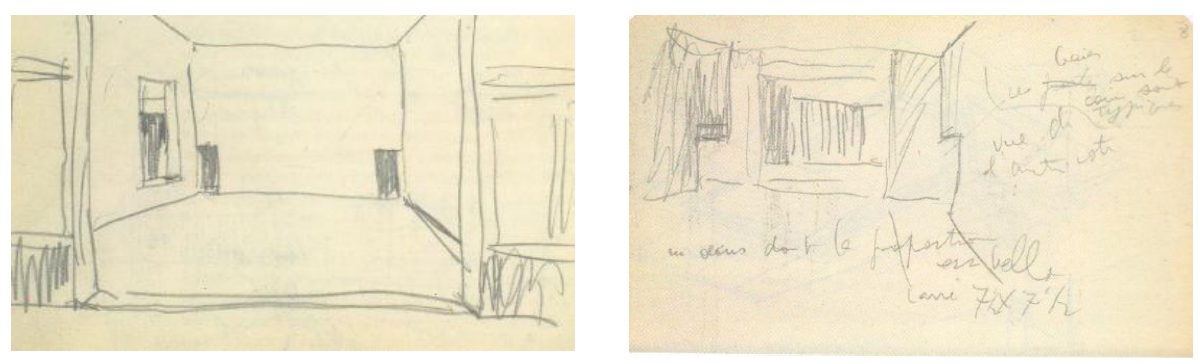

6 y 7.@FLC/ADAGP.Ch.É.Jeanneret, Salon de la Maison des Dioscures, Pompéi, Carnet 4, p.120-121.

\footnotetext{
${ }^{15}$ Única obra de referencia incluída dentro del primer volumen de la Oeuvre Complète.
} 
En el boceto, apenas se dibujan las pequeñas puertas encargadas de perforar la perfecta caja espacial, con lo que se evidencia la importancia del plano por encima del hueco, y así, percibir el espacio en toda su expresión. Le Corbusier lo especifica con más detalle: "les portes baies sur le...coin son typiques...vue de l'autre coté...un oecus dont la proprotion est belle carré 71/2 x 71/2“ (7). Proporción y límites, es la lección aprehendida y reflejada de nuevo en este jardin proyectado. De ello, se desprende toda la configuración final en la disposición y dimensión de los huecos realizados. De entre todos ellos, destaca la pequeña puerta, apenas perceptible, que comunica la estancia con el jardin, manifestando en ese momento, la clara separación entre el mundo interior y el exterior. La importancia de este hecho queda recogido en la fotografía que Le Corbusier realiza para el Pavillon del L'Esprit Nouveau @FLC/ADAGP L2(13)23(8).
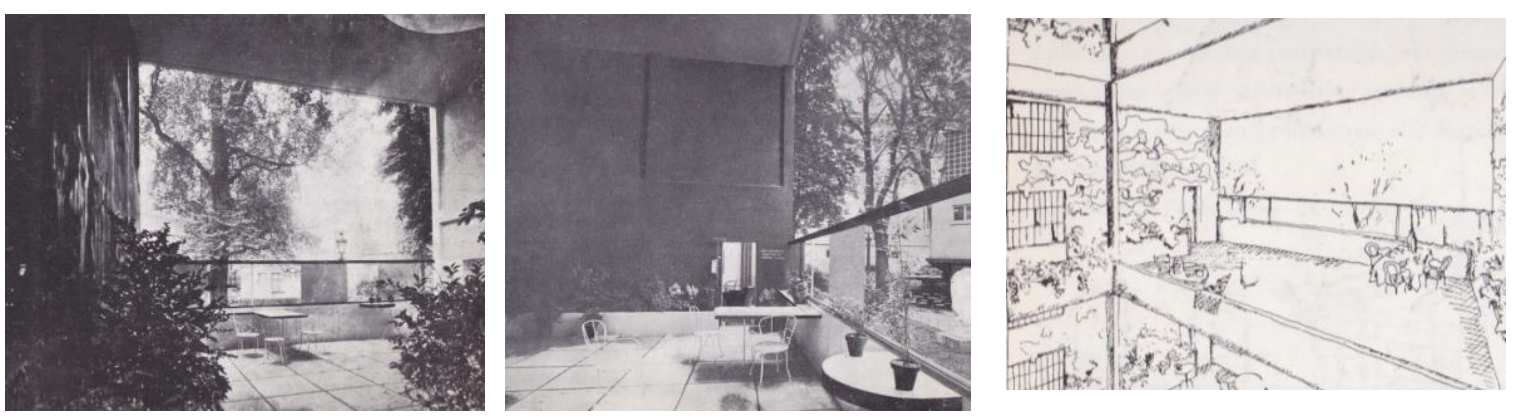

8.@FLC/ADAGP L2(13)23. Le Corbusier, Pavillon de L'Esprit Nouveau, 1925, ”le jardin-suspendu”, recogido en la Oeuvre Complète, p.95-103.

9. CFLC/ADAGP 19097, Le Corbusier, Croquis una terrasse-jardin (le jardin-suspendu).

Allí se evidencia que para conseguir toda la esencia -una caja de aire en perfectas proporciones -, sus planos laterales, apenas perforados, permiten encuadrar la visión del plano frontal. En palabras de Le Corbusier: "En este punto vital de la ciudad, se abre una puerta sobre el jardin. Este jardin es un pensil, cerrado en tres de sus lados [...] se puede pasear con los pies descalzos sin miedo al reumatismo, al resguardo del sol y de la lluvia [...] jardines eficaces, sin mantenimiento. Este jardin, captador de aire, multiplicado a lo largo de vastos bloques de edificios, en efecto constituye una verdadera esponja de aire. "l6

Le Corbusier también se ha valido del color sobre el paramento lateral para remarcar este hecho, un color, controlado y elegido dentro de la gama de colores de escala mayor que representará "la unidad y el equilibrio" frente a los colores dinámicos -no válidos para la construcción-. Aunque en Aprés le cubisme, Le Corbusier afirma que "La forma es preeminente, el color no es más que uno de sus accesorios. El color depende enteramente de la forma material: el concepto esfera, por ejemplo, precede al concepto color" 17 , lo cierto es que aquí, el color juega un importante papel en dirigir e intensificar la mirada hacia el exterior.

Por último, esta terrasse jardin o jardin suspendu, que también aparece representado en el boceto publicado en la Oeuvre Complète 1910-1929 (CFLC/ADAGP19097)(9), terminará percibiéndose como un interior, ya que la visión exterior quedará enmarcada por los elementos que construyen el límite: un antepecho ciego a $86 \mathrm{~cm}$ del suelo, y un perfil paralelo a $183 \mathrm{~cm}$. Ambos serán los mínimos elementos utilizados para redefinir la fenêtre en longueur. Es así como se irá construyendo la rica ambigüedad espacial.

Con la realización del Pavillon -como prototipo construído- y tras su inauguración el 10 de julio de 1925, Le Corbusier considera haber alcanzado uno de sus máximos logros aludiendo "celle-ci est une recherche patiente,

\footnotetext{
${ }^{16}$ Le Corbusier, Precisiones respecto a un estado actual de la arquitectura y el urbanismo,Barcelona:Apóstrofre, 1999, p.99.

${ }^{17}$ Ozenfant, A; Le Corbusier: Acerca del Purismo:Escritos 1918-1926, Madrid:El croquis, 1994. p.76.
} 
obstinée, d' une vérité que nous savons cachée sous la défroque lourde d'un passé écrasant, et celle vérité nous la percevons nettemente" 18 .

Esta búsqueda paciente y obstinada tiene como primer efecto la transformación del modelo realizado en 1922 al desarrollado en 1925. Le Corbusier trabaja con diversas posibilidades agregativas. Y así, en la propuesta dibujada para Boulogne-sur-Seine (@FLC/ADAGP 28791)(10), el corredor se dispone en una posición central junto al type que cruzará traversalmente el bloque, tanto superior como inferiormente.

Si analizamos, tanto los croquis interiores (OFLC/ADAGP 28797C) (11) como el croquis de la planta del rez-dechausée (@FLC/ADAGP28797D)(12), se observa un nuevo cambio en la apertura al jardin lateral. Esta se hace máxima, generándose un gran hueco que no reniega, ni de la posición, ni de la apertura, que ya existía en el Pavillon de l'Esprit Nouveau. La pequeña puerta continuará existiendo. Con esta nueva perforación en el muro de cierre al jardin, incluso se ha visto modificada la concepción espacial de la doble altura interior. Ahora el boudoir, se colocará, no con relación a la fachada exterior, sino paralelo al jardin suspendu.
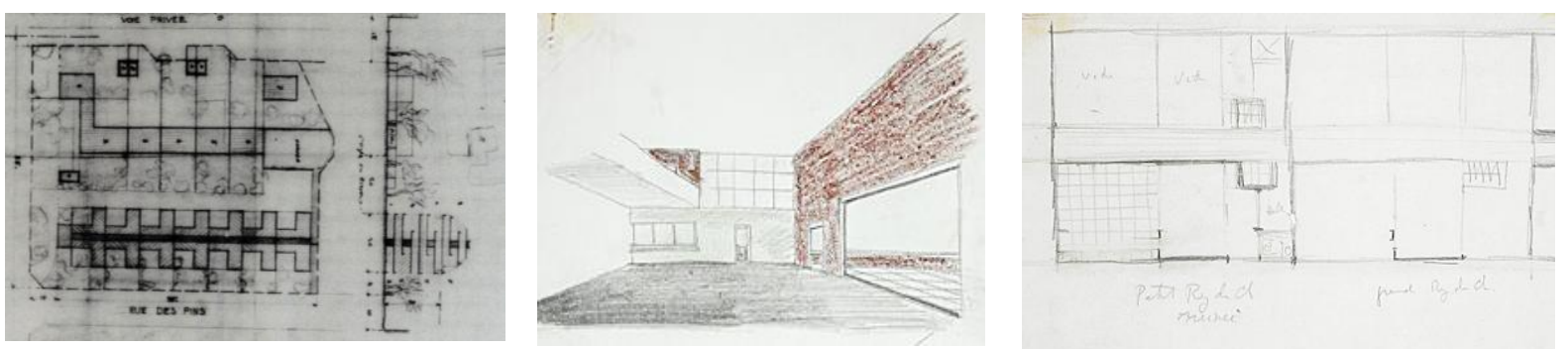

10.CFLC/ADAGP 28791, dessin d'étude en plan d'îlot aménagé et coupe en travers in situ, orientation, numérotation 11. $\mathrm{CFLC/ADAGP} 28797 \mathrm{C}$, Deux croquis en plan, croquis en coupe sur coursive intérieure entre deux types 12. OFLC/ADAGP 28797D, croquis d'étude petit rez-de-chaussée arrivée, grand rez-de-chaussée.
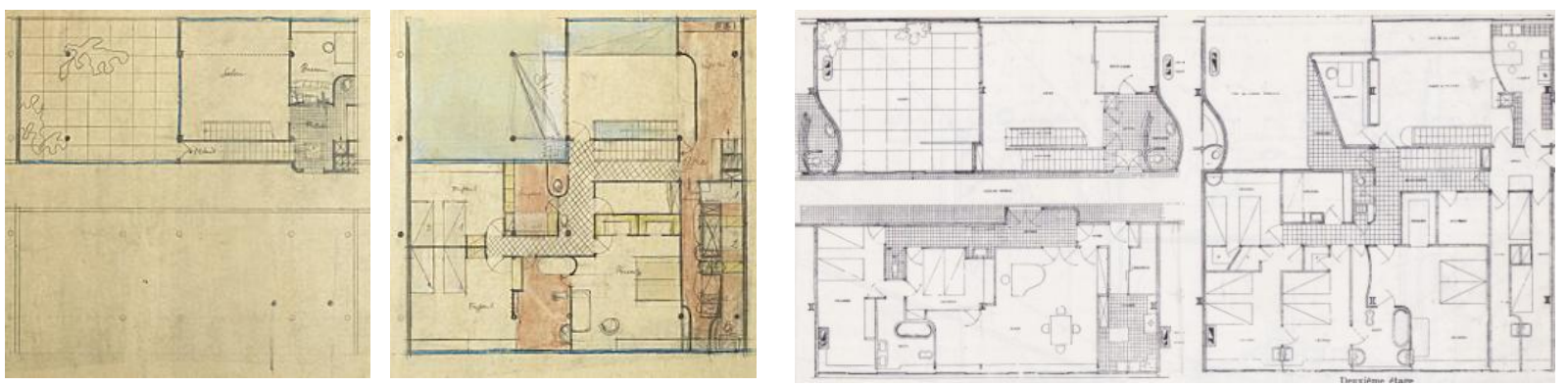

13. (FLC/ADAGP 08680 -Dessin d'étude de trois plans d'étage partiels.

14. CFLC/ADAGP29659 seire $n^{\circ}$ 1038/CFLC/ADAGP29660 serie $n^{\circ} 1039$ Type d'appartement d'un des grandes immeubles d'habitation, premier étage avec couloir general y deuxiemé etage.

Sin duda, la mayor transformación va a ser con el proyecto para el industrial Wanner, donde además de plantear el uso de la estructura metálica y, la idea de la maison à sec, también se irán precisando los tanteos realizados en los immeuble-villas. Son varios los tipos desarrollados para esta propuesta - type IGS, type 3CHM, type atelier P $o$ W, y type hôtel-, aunque como continuidad más próxima al immeuble-villa, nos centraremos sólo en el que se define como type de petit appartament. Sobre él, las variaciones se suceden, en un doble intento de encaje entre la modulación estructural y el desarrollo del tipo. En el dibujo (CFLC/ADAGP 08680) (13) todavía no se observa la variación métrica definitiva. Incluso, se puede comprobar que se recogen a la vez, dos fases modulares que se suceden durante el proceso del proyecto. Así, en la rez-de-chaussée, correspondiente a la

\footnotetext{
${ }^{18}$ Le Corbusier: L'Almanache d'Architecture,Les éditions G. Crès et Cie,Paris, FLC, 1925.p.134.
} 
planta del corredor, la vivienda ocupa la serie $\mathrm{A} 1 \frac{1}{2}-\mathrm{A}-\mathrm{A}-\mathrm{A} 1 \frac{1}{2}$. Mientras que en l'étage supérieur la relación ya ha cambiado, instalándose en una serie A-B-A-B. Finalmente, la propuesta dibujada (CFLC/ADAGP29659 serie $n^{\circ}$ 1038/CFLC/ADAGP29660 serie n ${ }^{\circ}$ 1039) (14) está dentro de un doble ritmo A, cuyo módulo A, corresponde por igual al jardin suspendu y a la sala.

Además de está continua revisión métrica, lo que si parece definirse es un nuevo volúmen superior que sobresale del plano lateral. En un principio, este volumen, que penetra en la caja espacial del jardin suspendu, aparecerá apoyado - se descubre en el pilar exento que aparece en el croquis de la Oeuvre Complète 1910-1929 (15) y en la organización estructural de l'étage supérieur (@FLC/ADAGP08680) (13) -, para finalmente, resolverse volado sobre el jardin suspendu dentro de la métrica de 2A, tal y como se observa en el croquis publicado en Oeuvre Complète 1910-1929 (16). En éste, se recogen los últimos cambios que afectarán a la relación entre el Jardin suspendu y la vida interior.
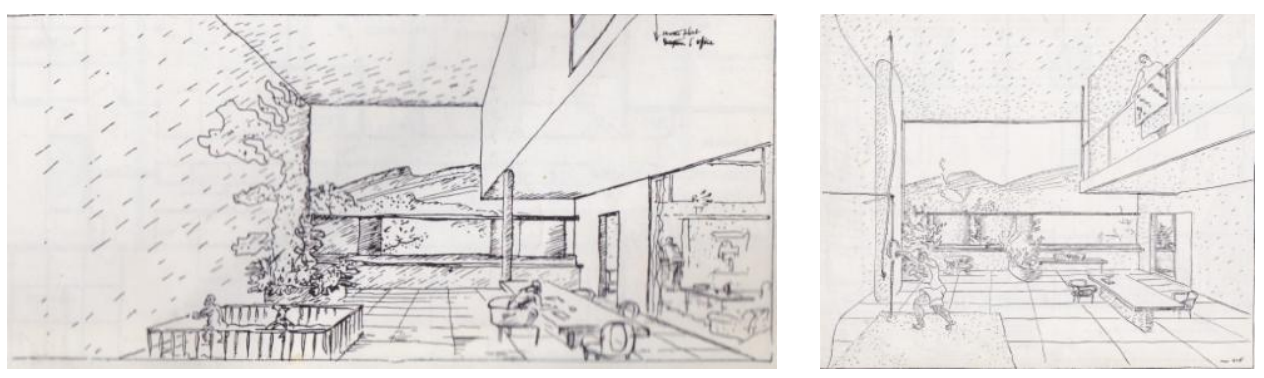

15.CFLC/ADAGP.Un jardin suspendu, Wanner Geneve,1928, Oeuvre Compléte p.183

16.๑FLC/ADAGP. Le jardin suspendu d'un appartement, Oeuvre Complète, p.182

Lo primero de todo, es la reducción en la relación espacial interior entre la salle à manger y la salle, a favor de una mayor valoración con el jardin. Sobre éste, recae el pequeño boudoir y la terrasse. Así, parece darse la necesidad de tomar partido por una de las dos relaciones ante el ajuste dimensional que ha provocado el cambio del sistema de agregación. Pero además, añadiría que se ha producido un doble proceso. Por un lado el jardin es la nueva estancia de la casa, aquella que permite - esta vez incluso de manera explícita - el esparcimiento y la actividad física. Por otro lado, es el lugar del que también participará la promenade arquitectónica interior. Basta con imaginar el recorrido de la primera escalera lineal dibujada. Ésta, se toma desde el hall de entrada y niega, desde el punto de arranque, cualquier relación con el jardin. Sin embargo, en su desembarco final, se abre directamente a la galería que vuelca sobre el jardin. Es el nuevo puesto de mando de la casa moderna. Con él, ha cambiado la forma de percibir y de estar. Lejos queda ya la caja espacial de proporciones perfectas que volcaba toda su esfuerzo en enmarcar la relación con el espacio exterior de manera análoga e independiente de la casa. Ahora, la vida ha pasado a un primer plano y el espacio del jardin suspendu se ha convertido en el centro vital al que se abre. Así se percibe en sus dibujos y en los "objetos” dispuestos.

\subsection{En la villa.}

Volviendo al mismo punto de arranque que para el apartado anterior, analizaremos ahora la variante última dibujada del Pavillon transformada en villa independiente para las villas de banlieue. El proyecto apenas ha cambiado en esquema (CFLC/ADAGP 23010)(17), demostrando que el uso del jardin no sólo es válido para la concepción del bloque colectivo sino también para la Villa en la periferia parisina. Características comúnes lo identifican: no se altera la pureza del prisma; el volumen sigue elevándose del plano del suelo; y en el muro 
lateral -sala-jardin-, apenas se perfora. Se evidencia la separación entre el mundo interior y el espacio exterior del jardin. Idea que no tardará en incorporarse a los encargos particulares de sus villas.

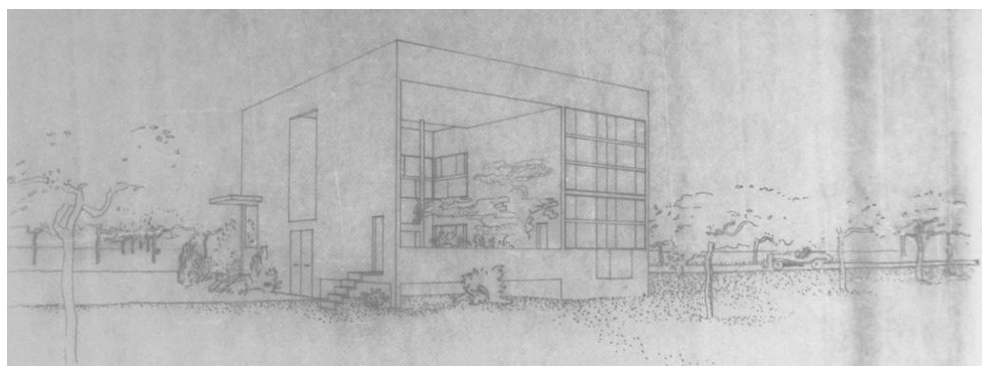

17. ()FLC/ADAGP 23010, Perspectiva variante L'esprit Nouveau, 1925.

\subsubsection{La Villa Meyer, 1925}

El proceso que analizamos comienza con la tercera propuesta ${ }^{19}$ dibujada para la Villa Meyer en abril de 1926. Después de abandonar las dos primeros esquemas ${ }^{20}$, Le Corbusier vuelve al prototipo del Pavillon. Su jardin suspendu couvert ${ }^{21}$, es producto de extraer del prisma compacto de Filebo una porción de masa de perfectas proporciones (18)(CFLC/ADAGP10371). De esta forma, se genera la vivienda tipo L que abraza el espacio exterior. Hasta aquí nada nuevo. Sin embargo la villa, al igual que ha sucedido con los immeuble-villa, también se ha visto afectada por las sucesivas exploraciones espaciales, desapareciendo por ello en este caso, el límite entre el jardin y el espacio interior de la casa. Este tanteo se evidencia muy bien en los croquis " 3 " $y$ " 4 " (@FLC/ADAGP 31514) (19) y en la rez-de-chaussée supérieur, donde se constata la gran apertura definida entre ellos, con un único elemento de cierre que permite la total conexión entre los dos mundos. Es claramente un anticipo al complejo mecanismo que surgirá para la villa Savoye; todo un hecho, que permite generar el gran espacio de relación propicio para los actos más sociales ${ }^{22}$.

Pero ¿Por qué esa excepción "ahora” sobre el prototipo?. Aún reconociendo la necesidad para la relación social, lo cierto es que otra idea parece clave para entenderlo. Analizando previamente el caso de la cellule del immueble-villa, o de su prototipo, el Pavillon de l'Esprit Nouveau, sabemos que ambos son herederos del tipo de la maison citrohan $^{23}$, y por ello, la sala asumía, como única posibilidad, la máxima relación con el exterior. Pero además, al tratarse de un modelo para la agrupación colectiva, Le Corbusier entiende que el jardin debe ser el espacio intermedio capaz de responder tanto a lo individual como a lo colectivo, protegiendo al habitante de las miradas indiscretas. De ahí, la escasa apertura de huecos en los planos que delimitan el jardin suspendu. Sin

\footnotetext{
${ }^{19}$ Sobre este punto se han encontrado ciertas discrepancias. En la obra, Le Corbusier et Pierre Jeanneret, Oeuvre complète, 1910-1929, este proyecto se recoge como el segundo, mientras que en las investigaciones de Tim Benton es denominado como el tercer proyecto. El segundo esquema, CFLC/ADAGP 29843, se corresponde con el proyecto e imágenes que Le Corbusier presenta a Meyer por carta.

${ }^{20}$ Benton, Tim: Le Ville di Le Corbusier e Pierre Jeanneret, 1920-1930, Milano:electaarchitettura, 2008.p.166-169.

${ }^{21}$ Boesiger, Willy: Le Corbusier et Pierre Jeanneret, Oeuvre compléte, 1910-1929, Zurich, Les Editions d'Architecture, 1973. croquis 4, ()FLC/ADAGP 31514, p.90

${ }^{22}$ Conviene recordar la carta que Le Corbusier escribe a Mme Meyer con motivo de la segunda propuesta dibujada. Aunque se está describiendo una solución arquitectónica diferente, queda clara la necesidad de un espacio para la relación social. “....si l'on veut jouer la comédie,l'on peu s'y vêtir, et deux escaliers permettent de descendre sur la scène, qui est au devant du gran vitrage..." “...si se quiere hacer comedia, sólo hay que vestirse para ello y bajar al escenario que esta ante la gran superficie acristalada ...” . Boesiger, Willy: Le Corbusier et Pierre Jeanneret, Oeuvre compléte, 1910-1929, Zurich, Les Editions d'Architecture, 1973. p.89

${ }^{23}$ Ver Nivet, Soline: Le Corbusier et l'immueble-villas, Stratègies, dispositifs, figures. Wrage, Mardaga cop.,2011
} 
embargo, en la Villa Meyer, la relación se invierte. Ya no existe necesidad de control visual con el interior, más bien al contrario, ya que la privacidad parece ahora necesaria con el mundo exterior. En este caso, será con la Folie Saint-James.
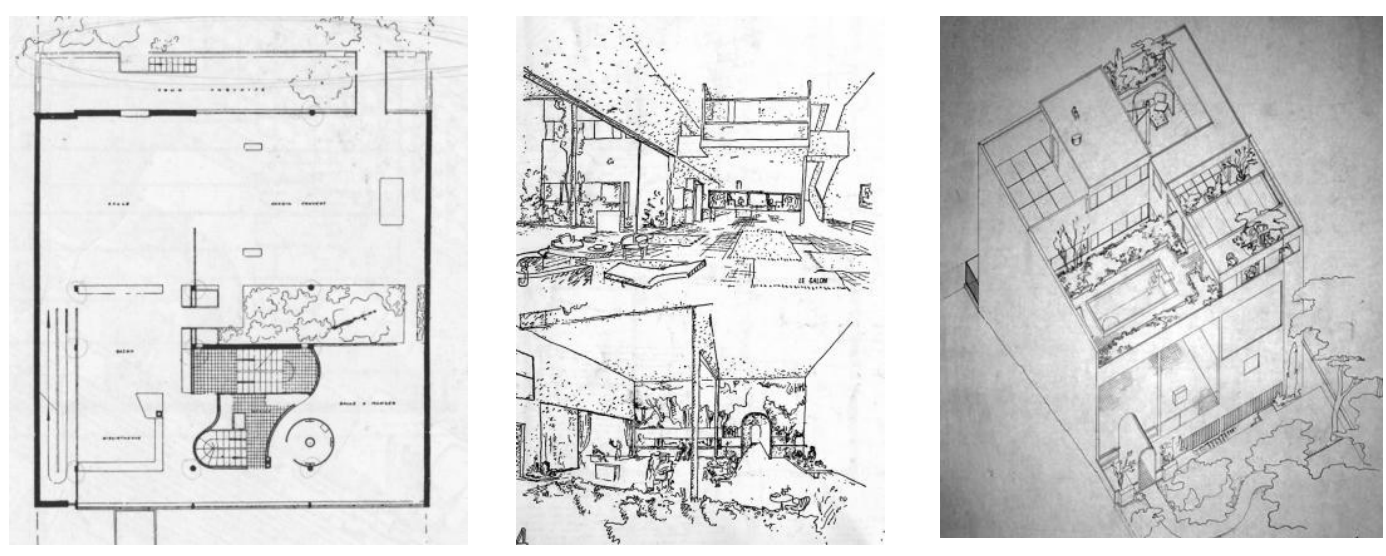

18. (CFLC/ADAGP10371, serie n ${ }^{\circ} 666$,Villa Meyer, Rez-de-Chaussée suréleve.

19. (CFLC/ADAGP31514, croquis 3y 4, le jardin suspendu couvert.

20. (FLC/ADAGP10380, Axonometría Villa Meyer,vista de la fachada a la Folie Saint-James

Para ello, Le Corbusier se vale de una doble acción: el tratamiento de los límites y la construcción de un patio inglés. Empezando por este último hecho, la decisión permite ventilar e iluminar la rez-de-chaussée inférieur y asegurar la privacidad de la villa, ya que al establecerse una grieta entre la casa y la Folie, la villa se hace solamente accesible a través del pequeño puente cubierto, a modo de muelle de acceso, que el arquitecto proyectará. Como se observa bien en la axonometría (CFLC/ADAGP10380)(20) la villa ya no queda sobreelevada de la cota del suelo, sino más bien, desconectada del mundo exterior. En la misma perspectiva, también se evidencia esta desconexión desde la fachada al jardin, colocando una mínima ventana allí donde antes se abría el balcón del immueble-villa. Dicha ventana ${ }^{24}$, que en el proyecto posterior de la Villa Ocampo no llegará ni siquiera a dibujarse, contrasta con la apertura total superior, una apertura, que permite la visión de la Folie Sain-James a través del boudoir interior ${ }^{25}$. Privacidad y disfrute del habitante están así ahora garantizados.

Métricamente la planta Meyer es, en este momento, un cuadrado de $17 \mathrm{mts}$ de lado. De las tres variantes dibujadas, dentro del esquema estructural CAAA (longitudinal) x $\mathrm{CAB}(\mathrm{A}+\mathrm{B})$ (transversal), el jardin suspendu couvert ocupa un doble módulo A. Esta medida implicará, de manera manifiesta, la construción de la crujía central -como se observa en el croquis 4 - y el pilar en fachada. Algo que no ocurría en el prototipo.

Para la última versión dibujada (@FLC/ADAGP10374)(21) la solución estructural y con ello, la concepción espacial del jardin, se verán transformados. Esta fase no queda recogida en la Oeuvre Compléte, y si lo comparamos con el proyecto definitivo, el cambio se produce al eliminar la cubierta en el último vano. Así, el jardin se separa del cierre lateral oeste (CFLC/ADAGP10378) (22).

\footnotetext{
${ }^{24}$ Incluso esta ventana no aparece tampoco dibujada para la primera variante del tercer proyecto recogido por Benton, Tim: Le Ville di Le Corbusier e Pierre Jeanneret, 1920-1930, Milano: electaarchitettura, 2008.p.174.

25 “...le boudoir voit les feuillages des grandes arbres" “...desde el "boudoir” se ven los follajes de los grandes árboles..." Boesiger, Willy: Le Corbusier et Pierre Jeanneret, Oeuvre compléte, 1910-1929, Zurich:Les Editions d'Architecture, 1973. p.89
} 

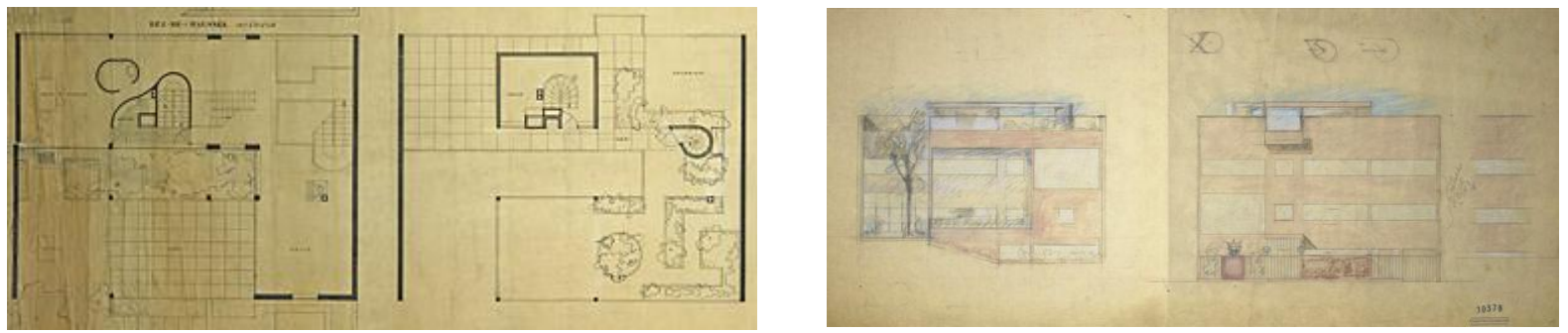

21. (OFLC/ADAGP10374, nº 691, Villa Meyer, etage, terrase. Versión definitiva junio 1926.

22. CFLC/ADAGP10378,dessin d'études de deux façades.Versión definitiva de junio de 1926.

El cambio favorece una mayor inclusión del mundo exterior, ocupando incluso, un módulo A completo. Quizás, se haya vuelto así a los orígenes geométricos que definían el jardin - AB (longitudinal) x AB (transversal)- , pero la decisión ha generado la ruptura de la caja espacial. Ahora, el jardin, que sigue levantándose unos centímetros del terreno natural, ha perdido la claridad de su propósito, entendiéndose más como un espacio exterior de transición.

\subsubsection{Villa Stein-de Monzie, 1927}

El rico proceso en la villa Stein-de Monzie surge principalmente con la serie de diseños preparatorios al segundo proyecto del 20 de julio de 1926. Las perspectivas realizadas entre junio y julio de ese mismo año, en palabras de Tim Benton, son la prueba evidente del intéres de Le Corbusier por la búsqueda de un cierto "gesto teatral" 26 a través de la serie de terrasses conectadas (CFLC/ADAGP10587). De ahí sencillamente viene el nombre que coloquialmente se le atribuye a la villa, Les Terrasses, fiel reflejo de la ideología lecorbusierana. En la axonometría a color (CFLC/ADAGP10587) (23) la promenade arquitectónica exterior queda garantizada gracias a la conexión de las terrazas a través del juego de escaleras lineales. Si seguimos observando este recorrido, no se presupone ninguna relación con la vida interior, sino más bien, y debido a la serie de perforaciones en los muros, una múltiple relación con el paisaje circundante. La llegada al jardin superior sólo es posible desde esta promenade exterior. No existe ningún acceso que comunique el interior con el jardin superior. Aún así, la idea no se descartará totalmente y la idea será el germen para las posteriores propuestas.
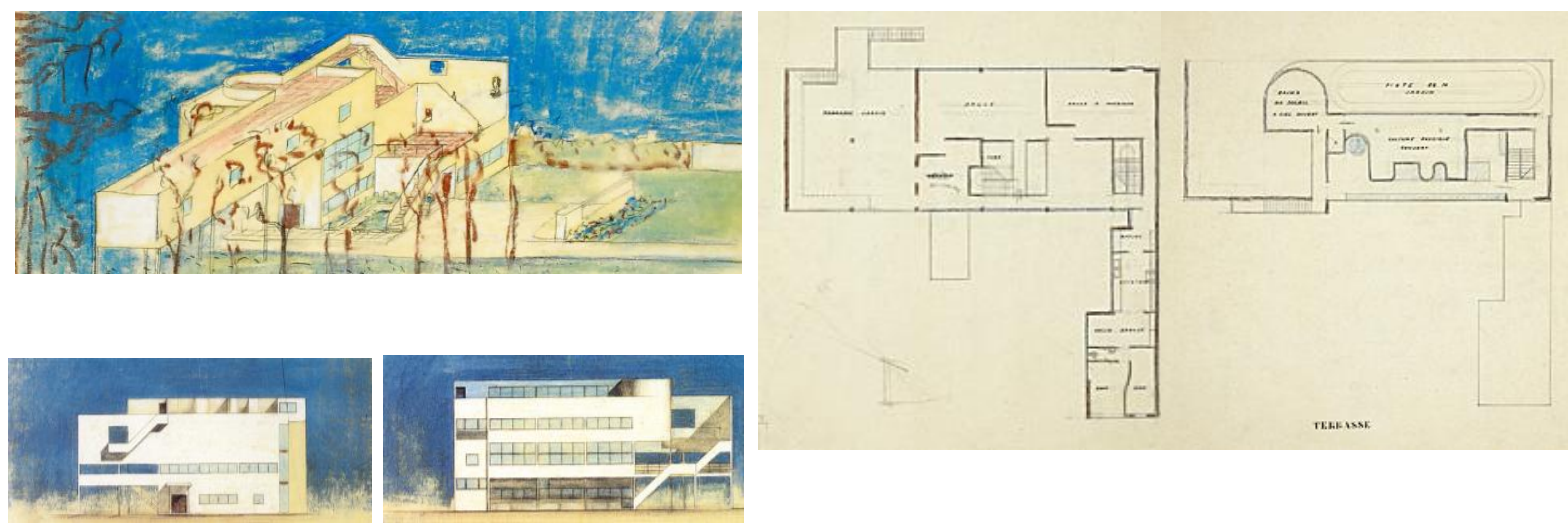

23. CFLC/ADAGP10587. Axonometría proyecto preparatorio al 20 de julio de 1926.

24.Proyecto preparatorio 20 de julio de 1926; @FLC/ADAGP10409, plans de rez-de-chaussée supérieur, serie $n^{\circ} 725$ y (C) FLC/ADAGP 10408, plans de la terrase serie $n^{\circ} 724$.

25. Alzados proyecto 20 de julio 1926:@FLC/ADAGP10406, sur y@ FLC/ADAGP10407, norte. Serie $n^{\circ} 722,723$.

\footnotetext{
${ }^{26}$ Benton, Tim. Le Ville di Le Corbusier e Pierre Jeanneret, 1920-1930, Milano, electaarchitettura, 2008.p.202.
} 
En los siguientes tanteos (@FLC/ADAGP10409 rez-de-chaussée supérieur y (@FLC/ADAGP10408 toitjardin)(24) el proyecto se vuelve más compacto -se ha reducido el ala de servicios en su lado oeste- , y el jardin suspendu o terrasse es colocado al lado este. Con ello, se rompe la simetría de los primeros bocetos. En esa posición el jardin se abrirá totalmente al sur, manteniendo en su lado norte, la relación con "el bosquecillo" que durante un tiempo fué del interés de Le Corbusier. Esta decisión en nada afecta a la promenade arquitectónica y al efecto escenográfico, que vuelve a surgir al conectar la rez-de-chaussée inférieur, la rez-de-chaussée supérieur y el toit-jardin. Para ello, Le Corbusier se vale del sistema de escaleras exteriores tanteado previamente. Éstas, serán concebidas en paralelo a los muros que encierran el jardin, provocando un continuo recorrido peatonal desde lo más público hasta el espacio más privativo - le toit-jardin .(OFLC/ADAGP10406),(@FLC/ADAGP10407)(25).

Este nuevo jardin es una nueva caja espacial abierta cenitalmente. El punto de vista elegido para el croquis denominado jardin surélevé (@FLC/ADAGP31480)(26), se produce desde la posición cubierta que recoge el solarium superior. Quizás por ello, el espacio se asimila más a un interior. Pero también, nacerá de otros mecanismos. Uno de estos, será la configurarán final de sus paramentos. Por un lado, la superficie con relación a la sala, se resuelve al igual que otros referentes construidos, donde apenas se dibujan dos puertas, que ni tan siquiera presentan una relación directa con la estancia principal, sino con dependencias de servicio (@FLC/ADAGP10409 rez-de-chaussée supérieur). En el plano posterior, a norte, la fenêtre en longueur cumpliendo ahora el papel real de rasgar el muro ciego de la fachada, y permitiendo la mirada hacia el jardin exterior. Y por último, al oeste, "la misma" ventana que enmarcará el paisaje, al igual que el final de recorrido peatonal dentro de la villa Savoye.

Con todo ello, y aunque la interrelación con la sala no existe, es cierto que el espacio abierto y acotado del jardin -abierto ahora cenitalmente-, la posibilidad de recorrer los espacios tanto interior como exteriormente, y la búsqueda de enmarcar la mirada hacia el paisaje, puede entenderse - y mucho - como la antesala a las ideas concretadas en la futura Villa Savoye. Aunque finalmente no será la propuesta elegida, si debieron ser importantes para Le Corbusier las investigaciones desarrolladas en esta solución, quedando recogidas en la Oeuvre Compléte.
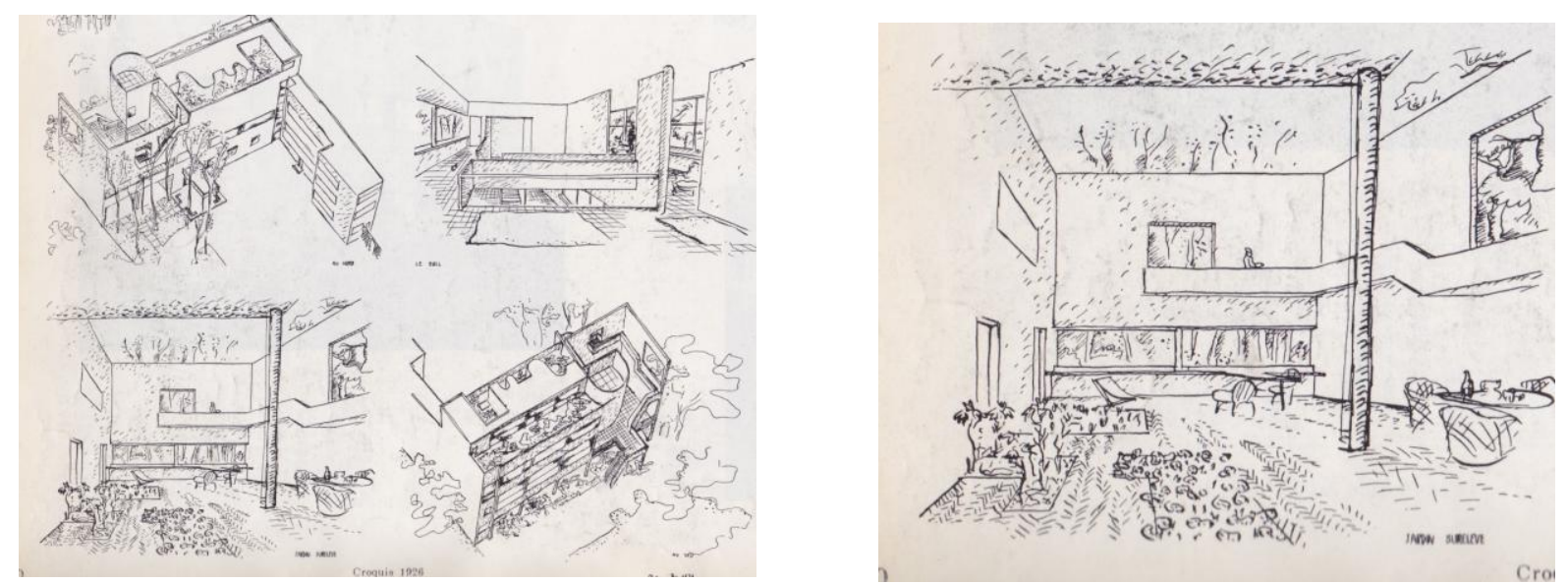

26. (FLC/ADAGP31480 Planche de présentation avec série de perspectives: vue génerale, vue au nord, vue au sud, croquis jardin Surélevé villa Stein,1926.

La solución que finalmente se va a construir, retoma la solución de una volumetría más compacta de los primeros bocetos. Un único volumen donde de nuevo el jardin suspendu cumple la función de vacío rodeado por un tipo $\mathrm{L}$ de vivienda. El esquema final recupera la trama ABABA. Y el jardin ocupa la misma métrica que la establecida en el prototipo del immeuble-villa-BA-. No obstante, llama la atención que para la definición de la 
terrasse-jardin couverte -como la denomina Le Corbusier en este caso-, ésta ya no dispone del elemento verde que matizaba la conexión visual con el ala posterior de la casa y que, al mismo tiempo, reconocía el hueco superior de la cubierta. Será en la villa Stein, donde el pavimiento llegará hasta el límite de la casa (27), ocupando toda la caja espacial. Puede entenderse este hecho, porque aquí, la terrasse-jardin construye el espacio íntimo y privado, elevándose una planta por encima de la cota del suelo y disponiendo previamente de una terrasse exterior que se convierte en la transición entre el jardin exterior y el jardin suspendu.
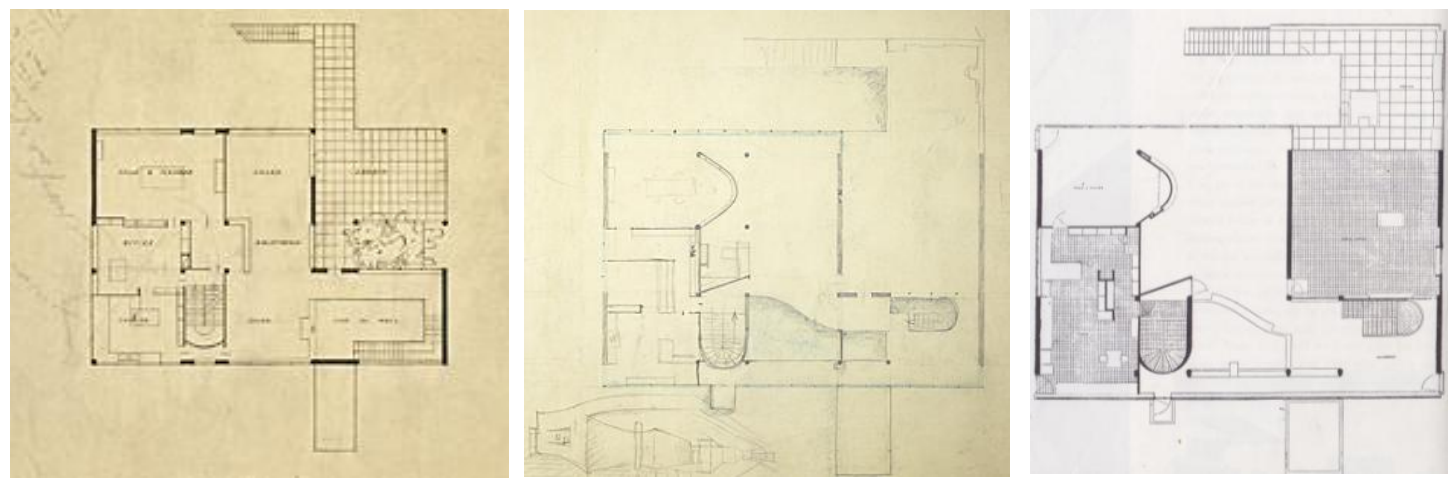

27. (OFLC/ADAGP10410 Rez-de-chaussée supérieur, serie $\mathrm{n}^{\circ} 769$, proyecto 7 octubre 1926. villa Stein.

28.@FLC/ADAGP10518 Rez-de-chaussée supérieur,esquema previo al proyecto de marzo de 1927.

29.@FLC/ADAGP Rez-de-chaussée supérieur,proyecto definitivo Villa Stein-de Monzie, 1927 publicado en la Oeuvre

Complète p.14

\subsubsection{Villa Savoye, 1928}

De la primera propuesta para la Villa Savoye, Jacques Sbriglio $^{27}$ se preguntaba cómo había sido posible que en un espacio de tiempo tan breve, Le Corbusier fuese capaz de presentar un proyecto tan acabado, pero la respuesta estaba obviamente en todo el proceso iterativo de los trabajos precedentes. Gracias a la experiencia acumulada, y siempre con el objetivo de afianzar las bases de la nueva arquitectura, el primer proyecto para la villa Savoye apenas se distinguirá del definitivo. Su relevancia también queda patente al quedar ambos recogidos dentro de la Oeuvre complète 1910-1929. Vol.1.y 2.
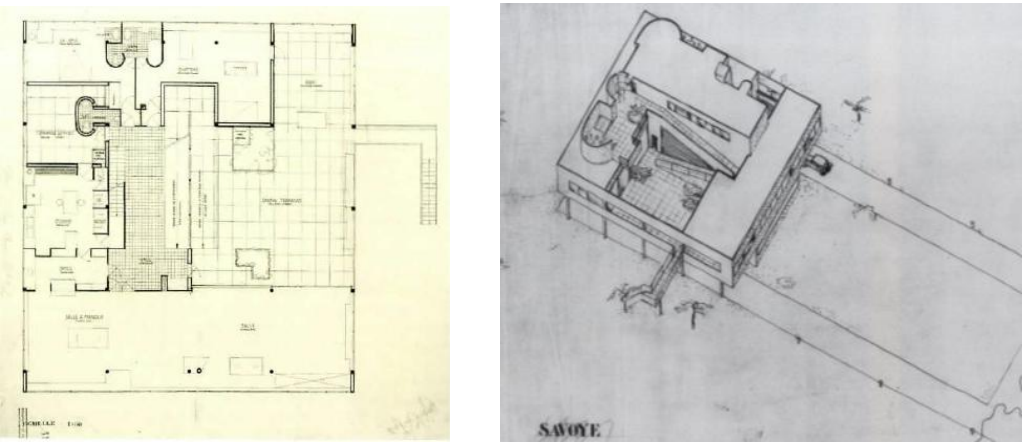

30. OFLC/ADAGP19412, primera propuesta villa Savoye, Rez-de-chaussée supérieur, octubre de 1928.

31. OFLC/ADAGP19423 Axonometría exterior villa Savoye.

${ }^{27}$ Sbriglio, Jacques: Le Corbusier. La villa Savoye. Madrid, ABADA Editores, 2005. 
En la descripción sobre la visita al emplazamiento, Le Corbusier ya presupone que "la casa no debe tener una única fachada", de ahí que la villa se presente elevada totalmente del plano del suelo ${ }^{28}$, y abierta en todos sus lados. Esto implicaba un cambio con respecto a los proyectos previos que habían sido organizados básicamente a dos fachadas. ¿Cómo concebir ahora el jardin? ¿A dónde abrirse?. (@FLC/ADAGP19412)(30). Comparándolo con los modelos precedentes observamos que éste ha dejado de ocupar una relación tangencial con la villa para convertirse en el lugar central, en "el alma de la villa" ${ }^{29}$.

El jardin rodeado por la vivienda, se abrirá a sur y al este, permitiendo en su nuevo acomodo, que la luz irradie hacia todos los recorridos y espacios interiores, principalmente al máximo mecanismo arquitectónico: la rampa. En parte, ella es la que dota a la villa Savoye de toda su esencia espacial. Al igual que aquella promenade arquitectónica exterior que recorría las terrasses de la villa Stein, ahora ésta se verá trasladada al interior, porque la arquitectura, cómo bien explica Le Corbusier, se aprecia “à la marche” ${ }^{30}$. Aún más, desde el eje principal de circulación -la rampa-, dispuesta simétricamente, se avanza internamente para llegar al jardin. Y sin dejar de recorrerlo, se ascendiende hasta el último elemento arquitectónico que definió Le Corbusier. De esta forma, el jardin suspendu parece haberse convertido en parte fundamental, no sólo como espacio para el descanso o la contemplación, que también, sino la razón de la intensidad lograda en uno de los principios que definen la villa: la promenade arquitectónica.

De todas formas, Le Corbusier parace no terminar de rechazar la conexión desde el exterior, y en su primer proyecto, y en los sucesivos tanteos motivados en parte para acortar el dilatado presupuesto, aparecerá siempre una sucinta escalera lineal (@FLC/ADAGP19413) (31) que conecta el jardin con la cota cero, escalera que mantendrá hasta el último momento. Lo que sigue reproduciendo aquí, es el recorrido exterior que descartó para la villa Stein.

Pero ¿Cómo se entiende este nuevo jardin supendu?. Nada queda del espacio "vertical” ideal que se definía en el Pavillon de l'Esprit Nouveau. Éste, ahora, se define con una estructura diferente (AAxAA), y abierto cenitalmente. Para poder aprehenderlo, al igual que ocurría con la propuesta no construida de la villa Stein, se construye todo el muro -horadado por la fênetre en longueur- y que recorre toda la casa. Eso permitirá definir el volumen perfecto de la caja sobre la parcela. Además, y junto a esta solución y su posición elevada, el espacio se ha transformado en una "estancia" de mayor intimidad, al igual que ocurría con los apartamentos de Wanner Geneve - ambos, proyectos coetáneos-. Es un auténtico "belvedere" moderno, razón por la que la sala principal se abrirá totalmente al jardin. Una decisión que se mantiene en todas las propuestas dibujadas. Ya no es necesario protegerse de miradas, más bien al contrario, el jardin es el espacio intermedio, a través del cuál se mira.

En la concepción de ese nuevo "impluvim" de luz y de aire, su localización le requirirá el esfuerzo técnico del gran paño de vidrio construido para la ocasión. Un impulso loable y necesario, pero que seguramente en la

\footnotetext{
28 “si uno está de pie sobre la hierba, no ve muy lejos. Por lo demás la hierba es malsana, húmeda, etc., para habitar en ella en consecuencia el verdadero jardin no estará a nivel del suelo sino por encima de éste, a tres metros y medio : será el jardin suspendido cuyo suelo es seco y solubre, y es desde este suelo desde donde se verá bien todo el paisaje, mucho mejor que si uno estuviera a bajo..." Boesiger, Willy: Le Corbusier et Pierre Jeanneret, Oeuvre compléte, 1910-1929, vol.2, Zurich:Les Editions d'Architecture, 1973. p.24.

${ }^{29}$ Sancho Osinaga, J.C.: El sentido cubista de Le Corbusier, Madrid : Munilla-Lería, 2000

${ }^{30}$ Boesiger, Willy; Stonorov,O: Le Corbusier et Pierre Jeanneret.Oeuvre Complète. 1910-1929, $11^{\circ} \mathrm{Ed}$, Zurich: Les Éditions d'Architecture, 1973.
} 
imaginación de Le Corbusier ${ }^{31}$ la importancia residía en dejar circular el aire, y con ello, que no existiera ninguna diferencia entre el interior y el exterior, convirtiendo la sala en el espacio porticado que se abre al jardin.

\section{Del vacío al lleno.}

Un último apunte, si hasta ahora hemos hablado de la concepción del jardín suspendu, como un proceso de sustracción o, de inclusión del vacío en una masa compacta, ¿de qué otro modo puede volver a construirse ese jardin confinado?

En su viaje a Italia Jeanneret se detiene a visitar Villa Adriana. Sobre este hecho escribirá más tarde; "Fuera de Roma, al aire libre, construyeron la Villa Adriana. Allí se medita acerca de la grandeza romana. Alli pusieron orden. Es la primera ordenación occidental de importancia, ${ }^{, 32}$. En su carnet A4, un joven Jeanneret dibujará uno de los muros más relevantes que constituyen el complejo entramado de Villa Adriana. Este muro es el encargado de delimitar el espacio del Pecile (32) ; una vasta explanada que determina el jardin interior donde la naturaleza se descubre artificialmente domesticada - centro camerelle con el bacino d'acqua-. El límite murario presenta una altura de 9 metros, y una forma totalmente cerrada y paralepipédica. Su lado más largo, de $400 \mathrm{~m}$, está orientado al norte-sur, mientras que el lado corto, se dispone en dirección este-oeste. A la construcción final del muro se le anexionará además una estructura techada y porticada. El conjunto, muro, cubierta y pórtico, permitía realmente los recorridos soleados en los días de invierno y la sombra fresca en los días calurosos. La estructura techada, en el momento en que lo dibuja Le Corbusier, ya ha desaparecido. Y en su visita sólo permanecerá en pie el muro norte. Aún así, para él, la presencia en solitario de este muro, no desmerece en absoluto, más bien al contrario, ya que permite "construir una sombra con la que protegerse del sol excesivo. Construir una sombra tan solo levantando un plano y dándole la orientación precisa. Resolver la cuestión con el gesto mínimo ${ }^{\text {‘33. }}$.

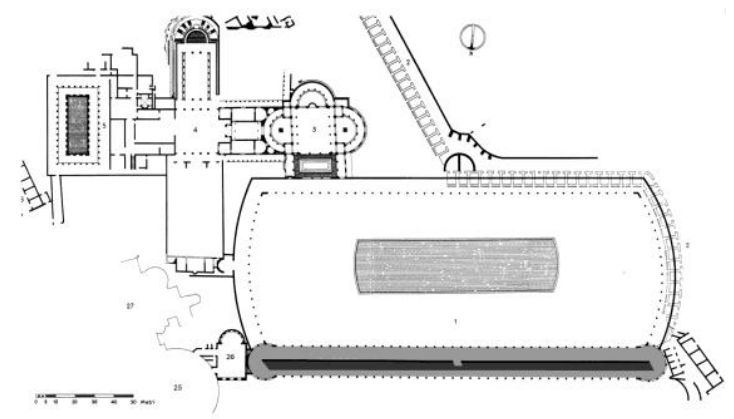

32. Plano del Pecile, Villa Adriana, Tivoli, siglo II d.c., extraído de Crescenzi, Livio; Hurtado de Mendoza, María; Rubini, Mauro, Ed. Ministerio per i Beni Culturali e Ambientali, Soprintendenza Archeologica per il Lazio, Roma, 1996.

Sobre la organización final, surgirá además la excepción en el lado norte del Pecile, dado que es aquí, donde el muro presenta un doble pórtico, uno a cada lado, convirtiéndose entonces éste en la espina central del paseo. Esta dualidad, también predice una nueva situación: la percepción simultánea del interior y del exterior a través

31 “ con mi amigo Durafour, dejé Argel una soleada tarde de invierno y volamos sobre el Atlas hacia las ciudades del M'Zab, en el tercer desierto en dirección sur...descubri el principio que rige las ciudades...tras los muros ciegos de las calles habia casas risueñas que se abrían con tres amplios arcos a un jardin exquisto". Le Corbusier:Aircraft, Madrid: ABADA Editores, s.1., 2003. p.34.

${ }^{32}$ Le Corbusier, Hacia una arquitectura, $2^{\circ}$ ed, Barcelona: Apóstrofe, 1998, p.126.

${ }^{33}$ Flores Soto, J.A., El uso consciente de la luz a través de varios espacios romanos, Revista de Humanidades y Ciencias Sociales, N $^{\circ}$ 8, marzo de 2011, ISNN- 1988-3927. p.44. 
del recorrido peatonal, ya que en su lado norte el recorrido se abría al paisaje, a la naturaleza, y en su lado sur, al interior del jardín proyectado. Esta misma idea presenta semejanzas a la utilizada por Le Corbusier en la promenade que encierra el jardin suspendu para la segunda propuesta de la Villa Stein.

El muro, despojado de todo la estructura techada, se convierte en una fuerte impresión a la mirada de Le Corbusier y con ello escribe: "las paredes se elevan al cielo en un orden tal que estoy conmovido. Siento vuestras intenciones. Sois dulces, brutales, encantadores o dignos. Me lo dicen vuestras piedras. Me unís a este lugar y mis ojos miran. Mis ojos miran cualquier cosa que enuncia un pensamiento “34. Más aún, con esta visión se intuye la constitución del espacio arquitectónico; "los antiguos construían muros, muros que se extendian y se enlazaban para ensancharse aun más. De este modo creaban volúmenes, base de la sensación arquitectónica, sensación sensorial “35. Pero también aseverará; "lo exterior es siempre un interior" 36. Esta afirmación, que aparece en Vers une Architecture, implicará para él que el exterior será la suma de masas y densidades, y de todo lo que le rodea -las casas vecinas, la montaña lejana o próxima, el horizonte bajo o alto -. Todas ellas se traducen en las "masas formidables que actúan con la potencia de un cubo". De esta forma, el exterior es presentido como un espacio limitado, un espacio que Le Corbusier dibuja descubriendo definitivamente la esencia del "édifice cube”, en los “100.000 mètres cubes" que es el exterior. Así la obra ya no está hecha solamente de sí misma, sino que para él, el exterior también existe. Esta idea se vuelve a recoger unos años más tarde en su libro Precisions; "El exterior me encierra en su todo, que es como un aposento" 37.

Estas dos realidades - el muro y el exterior- quedan fuertemente recogidas en el croquis que Le Corbusier levanta del muro Adriano (33). El mismo punto de vista dibujará Piranesi en 1770 para su compendio de "vedute di Rome" (34). Pero las aprehensiones serán bien distintas. Para Piranesi, la vedute del muro, deja subyugado a un hombre ante el esplendor inconmensurable de la ruina. Para Le Corbusier, el observador se encuentra próximo a la superficie muraria, intensificando la aprehensión espacial buscada: un “aposento”. Porque para él, el muro actúa construyendo el mínimo refugio, y define el orden a través del cuál se visualizará el paisaje. Surge así, el invariante arquitectónico, la forma por si misma, alejada de todo referente histórico.
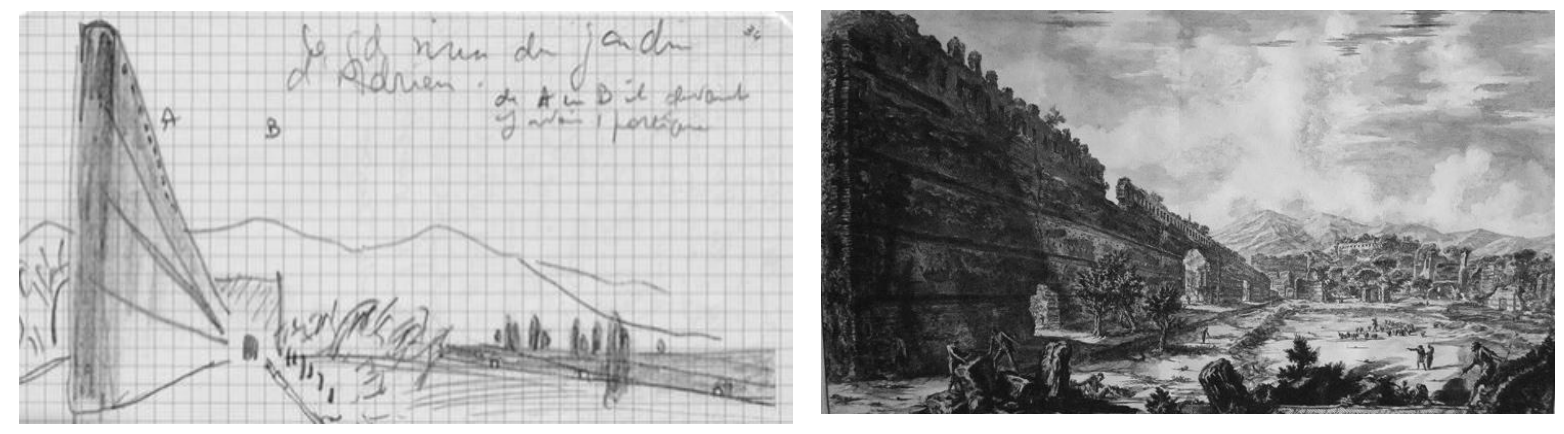

33. $\odot$ FLC/ADAGP Le Corbusier, Muro del Pecile en villa Adriano, Carnet A4, 1911

34. Piranesi, Vedute de Roma, Muro del Pecile en Villa Adriano. 1770.

\footnotetext{
${ }^{34}$ Le Corbusier, ref. 10, p.123.

${ }^{35}$ Le Corbusier, ref.10, p.150.

36 "El ojo humano, en sus indagaciones, gira siempre, y el hombre también gira simpre a izquierda y derecha, hace piruetas. Se aferra a todo y se siente atraído por el centro de gravedad del lugar entero. De repente, el problema se extiende en torno a él. Las casas vecinas, la montaña lejana o próxima, el horizonte bajo o alto, son masas formidables que actúan con la potencia de su cubo. El cubo de aspecto y el cubo real, son inmediatamente medidos, presentidos por la inteligencia. La sensación cubo es inmediata, primordial; vuestro edificio cubica 100.000 metros cúbicos, pero lo que cuenta son los millones de metros cúbicos que hay alrededor. Luego viene la sensación de densidad: un árbol, una colina, son menos fuertes que la disposición geométrica de formas.". Le Corbusier, ref. 10, p.154.

${ }^{37}$ Le Corbusier: Precisiones respecto a un estado actual de la arquitectura y del urbanismo, Ediciones apóstrofe,p.101.
} 
Le Corbusier realizará unos cuantos bocetos más en su paseo por Villa Adriana. Entre ellos se detiene en el interior de la exedra central, colocada justo simétricamente en el eje este-oeste del Pecile. Desde allí, el dibujo de Le Corbusier vislumbra un doble límite, el hueco de la exedra y el muro del Pecile, ambos, sucesivos límites sobre el límite exterior (35). ¿Y qué es esa visión sino una caja dentro de otra caja?. Claramente es advertido por Le Corbusier, e inseparable de las palabras que Quetglas le otorga a la villa Le Lac, "el cajón de la casa está dentro de otro cajón, el de la parcela, a su vez dentro de otro cajón mayor, el del camino, el sol y de los vientos y el paisaje ${ }^{38}$. Aunque con esta última reflexión nos adelantamos al análisis de la villa Le Lac, si comienza a tener cierto sentido que será esta doble impresión visual la utilizada por el arquitecto.
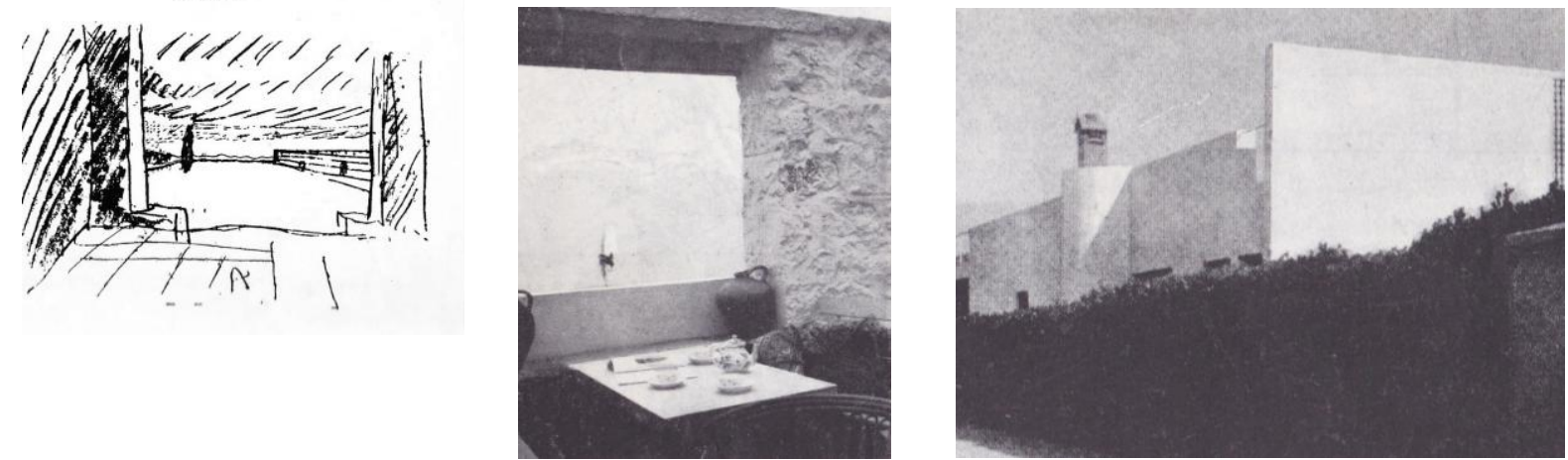

35. (CFLC/ADAGP. Croquis Le Corbusier, Muro del Pecile en la exedra central, Carnet A4, 1911

36. ()FLC/ADAGP.Le Corbusier, muro a poniente de la petit villa au bord du Lac Leman, 1925, Oeuvre Complète, p.74

37. (FLC/ADAGPLe Corbuier, muro y ventana a sur de la petit villa au bord du Lac Leman, 1925, Oeuvre Complète, p.74

Le Corbusier construye de nuevo el muro Adriano, o dicho de otra manera, es el muro el que permite la construcción de la primera caja espacial. Este muro adquerirá densidades diferentes, como reacción ante la casa y el lugar - al igual que ocurriría en la villa de Tívoli ${ }^{39}$-. En su lado oeste el muro se ensancha hacía todos los lados, sobresaliéndose de los límites de la casa. La razón, explicada también por Quetglas, es que ese muro “ve llegar al visitante [...] a su vez, [ y definiendo este plano] el lado norte es opaco, y el lado sur es una celosía que deja pasar la luz del sol de atardecida”. A su lado norte, y gracías a que la casa se coloca ligeramente por debajo de la cota de llegada, apenas se eleva, porque con el gesto de colocarse parece que ya se ha hecho todo lo necesario (36). En realidad, sobre este lado, la casa apenas se abre - al igual que la exedra circular que sirve de refugio a Le Corbusier en su visita- . Lo más importante acontece desde el sur y el este. Para ello, la caja-casa, debe posicionarse, y es aquí, donde surge el primer gesto moderno. La casa se situa hacia el poniente y el norte, alejándose de cualquier idea meramente compositiva, para aumentar la superficie en las zonas de mejor soleamiento y vistas ${ }^{40}$. El sol, y el aire, como afirmará tantas veces, son las joyas esenciales desde donde se generará su arquitectura.

Volviendo al muro exterior, es en su lado sur donde reacciona, como límite último de las cajas y el paisaje. El muro es primero apenas un pequeño antepecho, inapreciable desde la fenêtre en longueur interior de la casa, $y$ reconocible, como una fuerte linea horizontal, desde la pequeña loggia exterior ubicada en el lado este de la casa. Por último, en el límite este con la parcela, el muro se levanta por encima de esta primera linea horizontal,

\footnotetext{
${ }^{38}$ Quetglas, J : Le Corbusier. Mise au Point: "Como se construye una casita". Valencia: General Ediciones de Arquitectura, 2012, p.205

${ }^{39}$ igual que hablábamos del muro norte, ciego y que constituye la espina central del doble recorrido, interior y exterior. El muro en su lado oeste, se abrirá al paisaje a través de un continuo sistema de fenestración.

${ }^{40}$ Esta misma lectura sobre su disposición también se recoge en Quetglas, J. : Ref.38.
} 
adquiriendo, desde la distancia, el mismo valor que la casa en cuanto a presencia y definición, y al igual que en ésta, una única ventana permitirá la relación con el paisaje. Con ello, el recinto se hace habitable definiendo el espacio del jardin. Un lugar resguardado de las miradas, y "domesticado" gracias a la incorporación de los mínimos elementos necesarios con los que el hombre moderno habita: ventana, mesa y silla (37). Y un jardin suspendu que se levanta por encima de la cota del lago.

Ha pasado una década desde que Le Corbusier escribiera los principios que constituían el jardin para la casa de sus padres en Le-Chaux-de-Fonds, y todavía, estos siguen construyéndose inalterablemente de nuevo en la villa Le Lac. Sólo la forma es la que parece haber sufrido el proceso de racionalización y esencialización. Ahora parece nacer de un proceso distinto: primero, al confinar el espacio exterior a través del muro, y posteriormente, y en vez de sustraer, a la adicción del "sólido-casa". Entre ambos, surgirá, de nuevo, el vacío habitado: el jardin.

\section{Procedencia de las imágenes}

1. Type A (@FLC/ADAGP19176a), Rez-de-Chaussé et $1^{\circ}$ étage, Oeuvre Complète,vol.1, p.25.

2. Croquis $\subseteq F L C / A D A G P$ intérieur d'une maison dom-Ino, Oeuvre Complète,vol.1, p.25

3. Croquis @FLC/ADAGP5890, intérieur de la maison à Kasanlak, Oeuvre Complète,vol.1, p.17.

4. (FLC/ADAGP19221 Maison Dom-Ino. Propuesta de ordenación y volumetrías, Oeuvre Complète, p. 26

5.@ FLC/ADAGP07856, Alz. propuesta Cité ouvrière, 1920, Oeuvre Complète,p.29

6 y 7.@FLC/ADAGP.Ch.É.Jeanneret, Salon de la Maison des Dioscures, Pompéi, Carnet 4, p.120-121.

8.OFLC/ADAGP L2(13)23. Le Corbusier, Pavillon de L'Esprit Nouveau, 1925, "le jardin-suspendu”, recogido en la Oeuvre Complète, p.95-103.

9. OFLC/ADAGP19097, Le Corbusier, Croquis una terrasse-jardin (le jardin-suspendu).

10. CFLC/ADAGP28791, dessin d'étude en plan d'îlot aménagé et coupe en travers in situ, orientation, numérotation

11.๑FLC/ADAGP28797C, Deux croquis en plan, croquis en coupe sur coursive intérieure entre deux types 12. CFLC/ADAGP 28797D, croquis d'étude petit rez-de-chaussée arrivée, grand rez-de-chaussée.

13. OFLC/ADAGP 08680 -Dessin d'étude de trois plans d'étage partiels.

14. CFLC/ADAGP29659 seire $n^{\circ}$ 1038/OFLC/ADAGP29660 serie $n^{\circ} 1039$ Type d'appartement d'un des grandes immeubles d'habitation, premier étage avec couloir general y deuxiemé etage.

15.๑FLC/ADAGP.Un jardin suspendu, Wanner Geneve,1928, Oeuvre Compléte p.183

16.CFLC/ADAGP. Le jardin suspendu d'un appartement, Oeuvre Complète, p.182

17. CFLC/ADAGP 23010, Perspectiva variante L'esprit Nouveau, 1925.

18. OFLC/ADAGP10371,serie nº666,Villa Meyer, Rez-de-Chaussée suréleve.

19. OFLC/ADAGP31514, croquis 3y 4, le jardin suspendu couvert.

20. OFLC/ADAGP10380, Axonometría Villa Meyer,vista de la fachada a la Folie Saint-James

21. OFLC/ADAGP10374, nº 691, Villa Meyer, etage, terrase. Versión definitiva junio 1926. 
22. CFLC/ADAGP10378,dessin d'études de deux façades.Versión definitiva de junio de 1926.

23.OFLC/ADAGP10587. Axonometría proyecto preparatorio al 20 de julio de 1926.

24.Proyecto preparatorio 20 de julio de 1926; OFLC/ADAGP10409, plans de rez-de-chaussée supérieur, serie n ${ }^{\circ} 725$ y $\odot$ FLC/ADAGP 10408, plans de la terrase serie $n^{\circ} 724$.

25. Alzados proyecto 20 de julio 1926:@FLC/ADAGP10406, sur y@ FLC/ADAGP10407, norte. Serie ${ }^{\circ}$ 722,723 .

26. FLC/ADAGP31480 Planche de présentation avec série de perspectives: vue génerale, vue au nord, vue au sud, croquis jardin Surélevé villa Stein,1926.

27. OFLC/ADAGP10410 Rez-de-chaussée supérieur, serie nº 769, proyecto 7 octubre 1926. villa Stein.

28.@FLC/ADAGP10518 Rez-de-chaussée supérieur,esquema previo al proyecto de marzo de 1927.

29. OFLC/ADAGP Rez-de-chaussée supérieur,proyecto definitivo Villa Stein-de Monzie, 1927 publicado en la Oeuvre Complète p.14

30. OFLC/ADAGP19412, primera propuesta villa Savoye, Rez-de-chaussée supérieur, octubre de 1928.

31. OFLC/ADAGP19423 Axonometría exterior villa Savoye.

32. Plano del Pecile, Villa Adriana, Tivoli, siglo II d.c., extraído de Crescenzi, Livio; Hurtado de Mendoza, María; Rubini, Mauro, Ed. Ministerio per i Beni Culturali e Ambientali, Soprintendenza Archeologica per il Lazio, Roma, 1996.

33.OFLC/ADAGP Le Corbusier, Muro del Pecile en villa Adriano, Carnet A4, 1911

34. Piranesi, Vedute de Roma, Muro del Pecile en Villa Adriano. 1770.

35. OFLC/ADAGP. Croquis Le Corbusier, Muro del Pecile en la exedra central, Carnet A4, 1911

36. OFLC/ADAGP.Le Corbusier, muro a poniente de la petit villa au bord du Lac Leman, 1925, Oeuvre Complète, p.74

37. OFLC/ADAGP.Le Corbuier, muro y ventana a sur de la petit villa au bord du Lac Leman, 1925, Oeuvre Complète, p.74

\section{Breve Bibliografía}

Amirante, Roberta; Kütükçüoglu, Burcu; Tournikiotis, Panayotis; Tsiomis, Yannis: l'invention d'une architecte. Le voyage en Orient de Le Cobusier, Paris: Editions de la Villette, cop.2013

Aymonino, Carlo: La vivienda racional. Ponencias de los Congresos CIAM 1929-1930. Análisis de los elementos fundamentales en el problema de la "vivienda mínima". Le Corbusier y Pierre Jeanneret,Barcelona:Gustavo Gili, S.A.1973.

Benton, Tim: Le Ville di Le Corbusier e Pierre Jeanneret, 1920-1930, Milano:electaarchitettura, 2008.

Boesiger, Willy; Stonorov, O: Le Corbusier et Pierre Jeanneret.Oeuvre Complète. 1910-1929,vol.2. $11^{\circ} \mathrm{Ed}$, Zurich: Les Éditions d'Architecture, 1973.

Fundation Le Corbusier:Le Corbusier Plans, Volume 1,1905-1926.DVD, $1^{\circ}$ Ed, Paris: Echelle-1, 2005.

Giuliano Gresleri: Le CorbusierViaggio in Oriente, Paris:Foundation Le Corbusier, 1984.

Kepes, G: El lenguaje de la visión, $1^{\circ}$ ed, Buenos Aires: Infinito,1969. 
Le Corbusier: Hacía una Arquitectura,2ed, Barcelona: Apóstrofe, 1998.

Le Corbusier:Aircraft, Madrid: ABADA Editores, s.1., 2003. p.34.

Le Corbusier: Almanach d'Architecture Moderne,Paris:Les éditions G. Cres et Cia.,1925.

Le Corbusier: Precisiones respecto a un estado actual de la arquitectura y el urbanismo,Barcelona:Apóstrofre, 1999.

Moss, Stanislau Von: Le Corbusier, $1^{\circ} \mathrm{Ed}$, Barcelona: Lumen, 1977.

Nivet, Soline: Le Corbusier et l'immueble-villas, Stratègies, dispositifs, figures. Wrage, Mardaga cop.,2011.

Ozenfant, A; Le Corbusier: Acerca del Purismo:Escritos 1918-1926, Madrid:El croquis, 1994.

Sancho Osinaga, J.C.: El sentido cubista de Le Corbusier, Madrid : Munilla-Lería, 2000

Sbriglio, Jacques: Le Corbusier. La villa Savoye. Madrid: ABADA editores.2005.

Torres, Jorge; y otros: Le Corbusier. Mise au Point.Valencia: General ediciones de Arquitectura, 2012. 